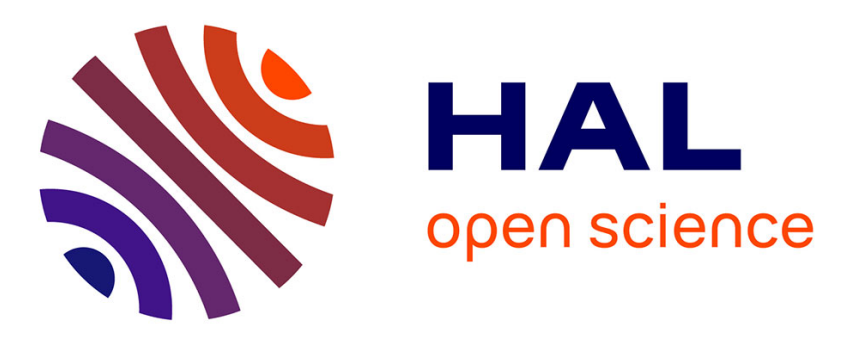

\title{
Effect of Annealing on Proton Conductivity of Aquivion-Like Proton-Exchange Membrane
}

Kamila Mugtasimova, Alexey Melnikov, Elena Galitskaya, Ivan Ryzhkin, Dimitri Ivanov, Vitaly Sinitsyn

\section{- To cite this version:}

Kamila Mugtasimova, Alexey Melnikov, Elena Galitskaya, Ivan Ryzhkin, Dimitri Ivanov, et al.. Effect of Annealing on Proton Conductivity of Aquivion-Like Proton-Exchange Membrane. Key Engineering Materials, 2020, 869, pp.367-374. 10.4028/www.scientific.net/KEM.869.367 · hal-03095876

\section{HAL Id: hal-03095876 https://hal.science/hal-03095876}

Submitted on 5 Jan 2021

HAL is a multi-disciplinary open access archive for the deposit and dissemination of scientific research documents, whether they are published or not. The documents may come from teaching and research institutions in France or abroad, or from public or private research centers.
L'archive ouverte pluridisciplinaire HAL, est destinée au dépôt et à la diffusion de documents scientifiques de niveau recherche, publiés ou non, émanant des établissements d'enseignement et de recherche français ou étrangers, des laboratoires publics ou privés. 


\title{
Effect of Annealing on Proton Conductivity of Aquivion-Like Proton- Exchange Membrane
}

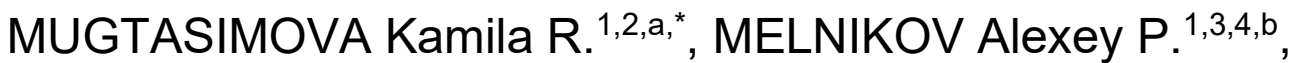 \\ GALITSKAYA Elena A. ${ }^{5,6, c}$, RYZHKIN Ivan A. ${ }^{5,6, d}$, IVANOV Dimitri A. ${ }^{1,3,4,7, e}$ \\ SINITSYN Vitaly V. ${ }^{5,6, f}$
}

${ }^{1}$ Moscow Institute of Physics and Technology, 9 Institutskiy per., Dolgoprudny 141700, Russian Federation

${ }^{2}$ Institute of General Physics, Russian Academy of Sciences, 38 Vavilova st., Moscow 119991, Russian Federation

${ }^{3}$ Institute of Problems of Chemical Physics, Russian Academy of Sciences, 1 Semenov av., Chernogolovka 142432, Moscow region, Russian Federation

${ }^{4}$ Lomonosov Moscow State University, 1-51 Leninskie Gory, Moscow 119991, Russian Federation

${ }^{5}$ Institute of Solid State Physics, Russian Academy of Sciences, 2 Academician Ossipyan, Chernogolovka 142432, Moscow region, Russian Federation

${ }^{6}$ InEnergy Group, 12-1 Elektrodnaya, Moscow 111524, Russian Federation

${ }^{7}$ Institut de Sciences des Matériaux de Mulhouse-IS2M, CNRS UMR 7361, 15 Jean Starcky, Mulhouse F68057, France

akamilamugtasimova@gmail.com, bmelnikov.al.pe@gmail.com, 'galitskaya@inenergy.ru,

di.ryzhkin@inenergy.ru, eivanov.da@mipt.ru, 'sinitsyn@inenergy.ru

Keywords: polymer electrolyte, sulfo group, proton conductivity, water in nanopores, temperature treatment

\begin{abstract}
Proton-conducting membranes were fabricated from a new short-side chain ionomer Inion (Russian analogue of Aquivion) by solution casting method. A series of temperature treatment experiments was conducted to show that annealing of Inion membranes at the temperature range from $160{ }^{\circ} \mathrm{C}$ to $170{ }^{\circ} \mathrm{C}$ leads to a significant increase of specific proton conductivity to values even higher than those of commercial membrane Nafion NR212. An explanation of this fact can be given by considering the membranes' proton transport mechanism and water behavior models in nanopores. Matching the proton conductivity mechanism of the membranes, which is realized in nanostructured channels with the diameter of about several nanometers according to the Grotthuss proton hopping mechanism, and the model of water and ice states in nanopores leads to the comprehensive understanding for the further optimization of the membranes to achieve high transport characteristic. For example, it can be improved by increasing the number of side-chain branches of the polymer.
\end{abstract}

\section{Introduction}

Fuel cells (FC) represent one of the most promising alternative energy technologies. $[1,2]$ They convert chemical energy directly into electrical energy without any intermediary steps. Nowadays, the hydrogen-air FCs based on proton-exchange membranes seem to be the most developed in comparison to all other types of FCs [2-7]. The basic requirements for the protonexchange membrane consist in high proton conductivity and mechanical strength, chemical resistance to the by-products of the reaction occurring in the FC, low gas penetration (crossover) to both fuel and oxidant, stability of power characteristics during long-term operation and reasonably low production costs.

The product of the American company DuPont ${ }^{\circledR}$ - proton-exchange membrane Nafion ${ }^{\mathrm{TM}}$ has become the first stable and most functional, in terms of basic parameters, solid polymer 
electrolyte for FCs. Currently, membranes of this type are the very common and often-used commercial products for the proton exchange membrane fuel cell (PEMFC) manufacturing. However, such membrane starts to rapidly degrade at temperatures above $90{ }^{\circ} \mathrm{C}$. This leads to degradation of the membrane's mechanical properties, and, even more importantly, to a sharp decay of its proton conductivity. Therefore, one has to limit the working temperature interval of PEMFC and in that case would face the problem of poisoning of the platinum catalyst on the electrodes due to the presence of impurities in the hydrogen fuel. The described problem, together with the high cost of the material, stimulates interest in developing possible alternative proton-conducting polymers for hydrogen-air fuel cells $[4,5,7]$.

In 2007, SOLVAY® commercialized a new perfluorinated sulfopolymer with shorter side chains in comparison to Nafion ${ }^{\mathrm{TM}}$ and called it Aquivion ${ }^{\circledR}$ [8]. Membranes with such morphology have higher proton conductivity, stronger water retention ability, and higher thermal stability. These advantages over long-side chain Nafion contributed by increased crystallinity intrinsic in short-side chaines membranes endow them with excellent PEMFCs performance and potentials for hightemperature operation [9]. More recently, a new promising method for synthesis of this polymer via water-emulsion copolymerization of fluoromonomers was proposed [10]. The method makes it possible to obtain Aquivion ${ }^{\circledR}$ ionomer material with a lower cost than commercial ionomer powder from the other manufacturers. However, up to date, there is no significant investigations of such materials yet. In particular, there is practically no information about the methods for the membranes fabrication from this ionomer and their physical and chemical characteristics.

As it was already mentioned, the most important characteristic of proton-exchange membranes is the value of its proton conductivity, and the improvement of it in one way or another allows one to increase PEMFC power characteristics. In this regard and in order to achieve high transport characteristics, the optimization of the manufacturing process is of special importance for the practical utilization of the new-type proton-exchange membrane as an electrolyte of fuel cells.

Thereby, the aim of this work is to obtain a new type of membranes (hereinafter, Inion membranes) from the ionomer solution and to study the influence of annealing temperature on the proton conductivity of the obtained membranes.

\section{Materials and Methods}

The proton-exchange membranes Inion were produced by casting from polymer solution. For this purpose, a small amount of ionomer solution, in this case, Russian analog of Aquivion ${ }^{\circledR}$ Inion - was uniformly cast on a glass substrate with $4 \times 4 \mathrm{~cm}^{2}$ area. The amount of the ionomer solution was selected experimentally; as a result, $0.8 \mathrm{ml}$ of $3 \% \mathrm{wt}$. solution was enough to form a thin film and optimal for uniform evaporation of the solvent throughout the entire thickness of the membrane without its cracking. To increase the thickness of the membrane, the same amount of solution was cast on the surface of the previous layer, dried at standard conditions for one hour. Thus, three layers of the solution formed a membrane with a thickness of approximately 20-30 $\mu$ m. Finally, the thermal treatment of membranes was carried out: experimental samples were annealed for 20 hours at fixed temperatures in the range from $80^{\circ} \mathrm{C}$ to $220^{\circ} \mathrm{C}$. All the prepared samples were exposed via the procedure of protonation and purification from organic impurities. For this purpose, the membranes were kept for 4 hours at $80{ }^{\circ} \mathrm{C}$ in a solution of $\mathrm{H}_{2} \mathrm{SO}_{4}$ and $\mathrm{H}_{2} \mathrm{O}_{2}$ and then purified from the acid by boiling in deionized water for one hour. The result of this procedure is shown in Fig. 1 where the photographs of the membrane sample before and after its purification are presented.

The proton conductivity of the obtained membranes was determined from the impedance spectra measured in the longitudinal direction using the 4-probe method. For this purpose, a membrane sample with dimensions $5 \times 35 \mathrm{~mm}$ was drained with filter paper and clamped between four platinum wire contacts $(\varnothing=1 \mathrm{~mm})$ in a custom-made cell, the construction of which was described in [10]. The cell was placed in a sealed thermostated glass container with water to maintain the condition of $100 \%$ humidity. Before the measurements, hydrogen was passed through 
the solution and working space of the cell heated to a prescribed temperature (i.e., 20, 30, 50 and $70^{\circ} \mathrm{C}$ ) for 1 hour. Impedance spectra were measured with an Elins P-40X spectrometer in the frequency range $0.5 \mathrm{~Hz}-50 \mathrm{kHz}$ in a potentiostatic mode with the amplitude of the applied voltage of $100 \mathrm{mV}$.
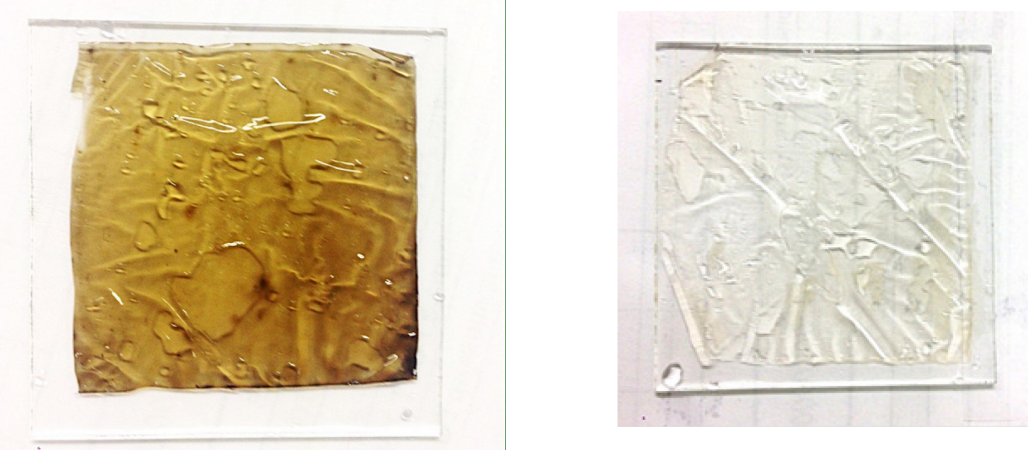

Fig. 1. Inion membrane after annealing (left) and after protonation and purification in a solution of $\mathrm{H}_{2} \mathrm{SO}_{4}$ and $\mathrm{H}_{2} \mathrm{O}_{2}$ for 4 hours at $80{ }^{\circ} \mathrm{C}$ (right)

It is well known, that when an alternating electric field is applied to an ionic (including proton) conductor, two currents flow in its volume: the current of moving charges ( $\left.\mathbf{j}_{\mathbf{d c}}\right)$ determined by the Ohm's law and the displacement current $\left(\mathbf{j}_{\mathrm{cm}}\right)$, determined by the time derivative of the displacement vector $D$. Therefore, the total alternative current $\mathbf{j}^{*}$ will be given by [11]:

$$
j^{*}=j_{d c}+j_{c m}=\sigma_{d c} E^{*}+\frac{\partial D^{*}}{\partial t}=\sigma E^{*}+\varepsilon_{0} E^{*} \frac{\partial E^{*}}{\partial t} .
$$

where the current density $\mathbf{j}^{*}$, the electric field $\mathbf{E}^{*}$, the electric induction $\mathrm{D}^{*}$ and the complex dielectric permittivity $\varepsilon^{*}$ are expressed in the complex form, $\sigma$ is the direct current ion conductivity and $\varepsilon_{0}$ - the dielectric constant. Considering that $\mathbf{E}^{*}=\mathbf{E}_{0} \mathrm{e}^{\mathbf{i} \omega \mathrm{t}}, \boldsymbol{\varepsilon}^{*}=\varepsilon^{*}-\mathbf{i} \varepsilon^{\prime \prime}$ (where $\varepsilon^{\prime}$ is the dielectric constant, and $\varepsilon^{\prime \prime}$ - dielectric losses) one can readily obtain:

$$
\mathrm{j}^{*}=\left(\sigma+\omega \varepsilon_{0} \varepsilon^{\prime \prime}\right) \mathrm{E}^{*}+\mathrm{i} \omega \varepsilon_{0} \varepsilon^{\prime} \mathrm{E}^{*}
$$

From $\mathrm{Eq}(2)$ one finds that the total $\mathrm{AC}$ conductivity can be written as:

$$
\sigma_{\mathrm{ac}}=\sigma+\omega \varepsilon_{0} \varepsilon^{\prime \prime}
$$

In real systems, along with the volume electrical response, the contribution of the interface resistance between the ionic conductor and electrode will appear due to the charge relaxation at this boundary. However, at frequencies of the electric field above the characteristic frequency of the charge relaxation at the interface, the contribution of the interface to the overall response becomes negligible in comparison with the volume contribution. In this frequency range and far from volume relaxation processes frequencies, the dependence of $\sigma_{\mathrm{ac}}(\omega)$ has the form of a plateau, whose extrapolation to zero frequency, in accordance with the expression (3), will yield the value of $\sigma$.

As an example, Fig. 2 shows the characteristic $\sigma_{\mathrm{ac}}(\omega)$ dependences, measured at different temperatures in the range from $20^{\circ} \mathrm{C}$ to $70{ }^{\circ} \mathrm{C}$ for the Inion sample, annealed at $170{ }^{\circ} \mathrm{C}$. One can see from this figure, that in the low-frequency region, which characterizes mainly the conductivity of the interface, with increasing of $\mathrm{f}=\omega / 2 \pi$ the value of $\sigma_{\mathrm{ac}}(\omega)$ increases monotonically and at $\mathrm{f} \geq 10 \mathrm{kHz}$ it reaches a plateau, corresponding to bulk conductivity. Extrapolation of this region to zero frequency (dashed line) gives the value of proton conductivity $\sigma$ at a constant current. Here it 
should be noted that the frequency interval, corresponding to bulk properties is not wide enough (less than a decade), that's why obtained values of $\sigma$ are just approximate. We also note that the value $\sigma$ can be determined from the impedance spectra Z' $(\omega)-Z^{\prime \prime}(\omega)$, which give almost the same values.

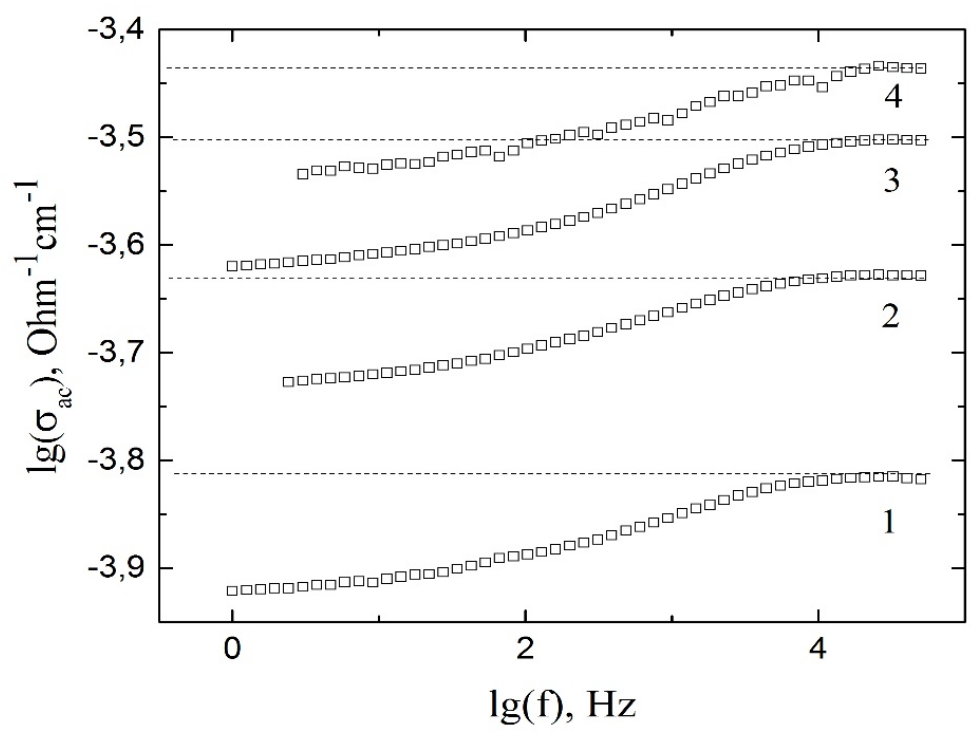

Fig. 2. Characteristic $\sigma_{\mathrm{ac}}(\omega)$ dependences at different temperatures $\left(1-20{ }^{\circ} \mathrm{C}, 2-30^{\circ} \mathrm{C}\right.$, $3-50{ }^{\circ} \mathrm{C}, 4-70{ }^{\circ} \mathrm{C}$ ) for a sample annealed at $\mathrm{T}_{\mathrm{an}}=170^{\circ} \mathrm{C}$. The dashed line shows extrapolation of the bulk conductivity to zero frequency, which determines the value of $\sigma$

If in the experimental system the charge transport is represented by only one type of charge carrier, the conductivity value $\sigma$ can be written as:

$$
\sigma=\mathbf{q n} \mu,
$$

where is the charge of current carriers, is their concentration and $\mu$ - the mobility of the charge carriers.

In the studied proton-conductive membranes the concentration can be determined by the water content (moisture content) in the sample; under the experimental conditions, when measurements were carried out at $100 \%$ humidity and far from the destruction temperature, the concentration $\mathrm{n}$ is constant throughout the temperature range. Therefore, the temperature dependence of the conductivity, according to Eq. 4, can be determined by the temperature dependence of the proton mobility. According to the Nernst-Einstein equation, mobility can be expressed in terms of the diffusion coefficient [12]:

$$
\mu=\frac{\mathrm{qD}}{\mathrm{kT}}=\frac{\mathrm{qvl^{2 }}}{6 \mathrm{kT}}=\frac{\mathrm{qv}_{0} \mathbf{l}^{2}}{\mathrm{kT}} \mathrm{e}^{\frac{\mathrm{E}_{\mathbf{2}}}{\mathrm{kT}}},
$$

where is the charge of an ion, is the diffusion coefficient, $v$ is the frequency of their jumps, $v_{0}$ is the frequency of touching the energy barrier by the ion, is the effective jump length and $\mathbf{E}_{\mathbf{a}}$ is the activation energy of ion migration.

Combining Eq. 4 and Eq. 5, one can get:

$$
\sigma=\frac{\mathbf{q}^{2} \mathbf{n v}_{0} \mathbf{l}^{2}}{\mathrm{kT}} \mathrm{e}^{-\frac{\mathrm{E}_{\mathbf{z}}}{\mathrm{kT}}}=\frac{\mathbf{A}}{\mathrm{kT}} \mathrm{e}^{\frac{\mathrm{E}_{\mathbf{a}}}{\mathrm{kT}}}
$$

where $\mathrm{A}$ is the pre-exponential factor. 
It can be seen from the Eq. 6 that proton conductivity dependences will have a linear character in the $\ln (\sigma \mathrm{T})-1 / \mathrm{T}$ coordinates; indeed, this was observed during the investigation of Inion membranes, annealed at different temperatures, as it is shown in Fig. 3. In addition to the dependencies of studied membranes, the temperature dependence of the proton conductivity of the commercial Nafion NR212 membrane is also shown in Fig. 3 for comparison.

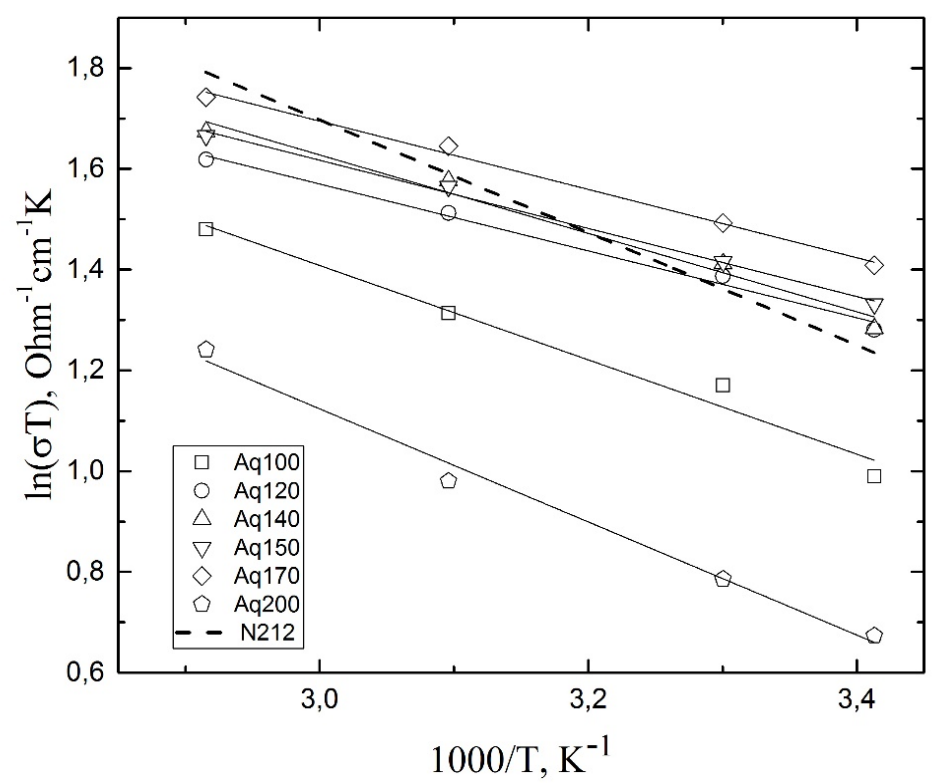

Fig. 3. Temperature dependences of proton conductivity of Inion membranes annealed at different temperatures plotted in the $\ln (\sigma \mathrm{T})-1 / \mathrm{T}$ coordinates. The annealing temperatures are represented on the legend. Dashed line corresponds to the proton conductivity of the commercial membrane Nafion NR212

The specific proton conductivity dependence of the fabricated Inion membranes measured at room temperature $\left(20^{\circ} \mathrm{C}\right)$ is shown in Fig. 4 as a function of the annealing temperature. It can be seen that annealing in the temperature range from 160 to $170{ }^{\circ} \mathrm{C}$ is optimal for obtaining membranes with high transport characteristics. Annealing at $\mathrm{T}_{\mathrm{an}}=200^{\circ} \mathrm{C}$ leads to a sharp decrease in $\sigma$, which is due to the onset of the chemical decomposition of the polymer matrix.

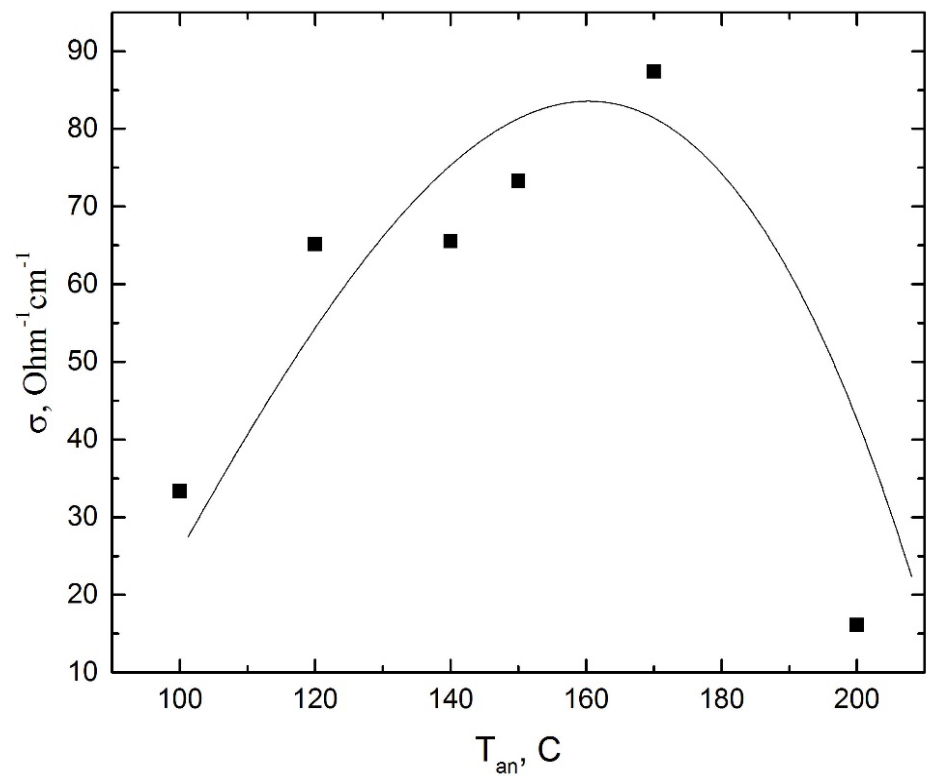

Fig. 4. Specific proton conductivity dependence of the Inion membranes measured at room temperature $\left(20^{\circ} \mathrm{C}\right)$ as a function of the previous annealing temperature $\mathrm{T}_{\mathrm{an}}$ 
The activation energies, calculated from the dependences shown in Fig. 3, for all investigated Inion membranes were $\mathrm{E}_{\mathrm{a}} \approx 0.1 \mathrm{eV}$, which is much less than the activation energy of a Nafion NR212 membrane, where $\mathrm{E}_{\mathrm{a}} \approx 0.25 \mathrm{eV}$. The experimental data, known to date, shows that the transport characteristics and dielectric properties of water in nanopores strongly depend on the membrane morphology and its pore size [11-14]. In this connection, it can be assumed that the lower activation energy $E_{a}$ of samples based on the Aqiuvion-like polymer may be due to a smaller diameter of the proton transport channels in the matrix of such a polymer than the diameter of the Nafion NR212 polymer channels. In accordance with the microscopic model developed in [16], a decrease in the dimensions of the channels leads to an increase in the concentration of bond defects and, consequently, to a decrease in the activation energy $E_{a}$ of the migration process, which is observed in our investigations (Fig. 3)

As one can see from the Eq. 6, along with the activation energy, the concentration of mobile protons $\mathrm{n}$, controlled by the moisture content in the samples, also has a large effect on the conductivity value. In this connection, it can be assumed that the annealing of Inion membranes at different $\mathrm{T}_{\text {an }}$ leads to a change of the moisture content.

\section{Discussion}

The most important results of this work include high values of low-frequency conductivity, low activation energy, and a non-monotonic dependence of conductivity versus the annealing temperature of the samples. These results can be explained within the framework of a simple proton transport model. Such model and understanding of the details of proton transport will be helpful while designing new possible ways for further increase of the proton-conducting membranes' efficiency.

We suggest that the proton transport in Aquivion-like membranes, as in other types of polymer membranes, proceeds through water, confined in the nanostructured channels (the diameter is about several nanometers) according to the Grotthuss mechanism. Moreover, the works $[15,16]$ showed the similarity of proton transport mechanism for different PFSA membranes. The specificity of the proposed model is the special condition of water in channels with such small dimensions, first studied in [17] and used to describe the quasi-liquid surface layer of ice in ref. [18]. This state of water is characterized by a crystalline tetrahedral oxygen lattice, possibly with significant deformations, and definitely with disordered proton sublattice. A similar state is realized in many solid electrolytes when one of the sublattices can be melted, and the second maintains its structure. In the case of water, the disorder of the proton sublattice means numerous deviation from the ice rules, i.e. presence of bond defects and ion defects, which are current carriers in ice and water [19-21]. The reasons for the deviation from the rules of ice and the occurrence establishment of special state are the temperature and the interaction between water molecules adjacent to the channels' walls and molecules of the polymer matrix. Similar reasons (the special nature of surface ordering and temperature) lead to the appearance of a quasi-liquid surface layer of ice and to the melting of bulk ice. But for ice in nanopores, the channel walls play a stabilizing role, and the state of ice with the liquid state of hydrogen bonds can be kept at temperatures well above the melting temperature of bulk ice. The same state of water can be realized at very high pressures. In this case, high pressure plays a stabilizing role; in [20], such a state was called metallic ice or the superionic state of ice. The detailed description of the proposed model is described in the works [19-20].

This state of ice model is considered in [17]. This theory explains the reasons for the high proton conductivity of ice. A more detailed description of this model will help us to further understand the processes occurring in the nanopores of the membrane. First of all, it is worth noting the fact that the low-frequency conductivity of "pure" ice is of the order of $10^{-9} \mathrm{~S} / \mathrm{cm}$. While the transition to a liquid state with a complex system of hydrogen bonds, the concentration of ionic defects increases by about 6 orders of magnitude [17], i.e. the low-frequency conductivity should become of the order of $10^{-3} \mathrm{~S} / \mathrm{cm}$. The temperature increase from $0^{\circ} \mathrm{C}$ to $20{ }^{\circ} \mathrm{C}$ leads to the conductivity increase up to $2.5^{*} 10^{-3} \mathrm{~S} / \mathrm{cm}$, which is lower than the specific proton conductivity of our samples, but close to the conductivity of membranes annealed under the most non-optimal 
conditions. Also, it should be mentioned that the conductivity of the metal phase, obtained from pure ice, was estimated. As numerical estimations [17] show, under these conditions only one from a million oxygen sites is occupied by an ionic defect.

This means that the introduction of impurities, leading to the formation of ionic defects, even at a concentration of $10^{-4}$, can increase the low-frequency conductivity by two orders of magnitude, up to $2,5^{*} 10^{-1} \mathrm{~S} / \mathrm{cm}$. This is already higher than the conductivity of our samples. The impurities that lead to the doping of ionic defects can be both acids remaining in the pores and side branches with acid residuals at the end. In the first case, to increase the conductivity of the membranes, it is recommended to add acid to the water with a relative concentration of about $10^{-4}$ (this should give the conductivity indicated above). In the second case, the number of side branches should be increased, which is probably happens when the samples are annealed.

Concerning the low activation energy, it is interesting to note that the measured value of 0.1 $\mathrm{eV}$ is close to the value of the activation energy of bond defects in a liquid state with hydrogen bonds, which is $0.09 \mathrm{eV}$ [17]. If this coincidence is not accidental, then the general model should be as follows. The behavior of water molecules near hydrophobic walls' sections (which are the most area of the walls in the Inion channels) is similar to the behavior of water molecules near the free surface of ice (the boundary with air is an ideally hydrophobic case). According to this analogy, ordering at the interface leads to the doping of bond defects into the water in the channel, i.e., its transition to a liquid state with a system of hydrogen bonds. In turn, this process leads to an increase of ionic defects concentration, which determines the low-frequency proton conductivity. But this growth is insufficient to explain the observed abnormally high conductivity. For such an explanation, it is necessary to assume the presence of acid residuals either in water or at the ends of the lateral branches. If the concentration of ionic defects (as a result of doping) is equal to or higher than the concentration of bond defects, then the latter will be the bottleneck that can limit the conductivity. This circumstance can explain the described above coincidence of activation energies.

\section{Conclusions}

The experimental results obtained in this work indicate that for a fixed annealing time of 20 hours there is a temperature range $\left(160{ }^{\circ} \mathrm{C}-170^{\circ} \mathrm{C}\right)$ in which the thermal treatment leads to the maximum values of the specific proton conductivity of solution-casted Inion membranes, exceeding the values of the specific proton conductivity of the commercial membrane Nafion NR212. The studied membranes are of undoubted interest as they can be practically used in effective hydrogenair fuel cells. The proton transport model was proposed; this model can be effectively used for further optimization of Inion membranes.

\section{Acknowledgments}

The authors greatly thank the Ministry of education and science of the Russian Federation (contract № 05.605.21.0188 from 3 December 2019 (RFMEFI60519X0188)) for financial support. The work was done on the theme of state task № 0074-2019-0014 (registration № AAAA-A19119101590029-0).

\section{References}

[1] E4tech, Fuel Cell Industry Review (2019)

[2] Y. Wang, D. Diaz, K. Chen, Z. Wang, X. Adroher. Materials, technological status, and fundamentals of PEM fuel cells, Materials Today. 32 (2020) 178-203.

[3] S.I. Kozlov, V.N. Fateev, Fuel cells - promising chemical sources of electrical energy, Alternative fuel vehicles. 2 (2014) 7-23.

[4] Yu.A. Dobrovol'skii, E.V. Volkov, A.V. Pisareva, Yu.A. Fedotov, D.Yu Likhachev, A. L. Rusanov, Proton-Exchange Membranes for Hydrogen-Air Fuel Cells, Russian Journal of General Chemistry. 77 (2007) 766-777. 
[5] L. Carrette, K.A. Friedric, U. Stimming, Fuel cells - fundamentals and applications, Fuel Cells. 1 (2001) 5-39.

[6] A. Kraytserg, Ya. Ein-Eli, Energy \& Fuels, 28 (2014) 7303-7330.

[7] F. Barbir, ed. by N, Sammes, PEM Fuel Cells, Springer London, London, (2006) 27-51.

[8] Information on http:/www.solvay.com/en/markets-and-products/featured-products/ Aquivion.html

[9] J. Li, M. Pan, H. Tang, Understanding short-side-chain perfluorinated sulfonic acid and its application for high temperature polymer electrolyte membrane fuel cells, RSC Adv. 4 (2014) 3944-3965.

[10] S.S. Ivanchev, M.R. Tarasevich, V.A. Bogdanovskaya, O.V. Korchagin, E.V. Burkovskii, O.N. Primachenko, V.S. Likhomanov, Performance of the Hydrogen-Air Fuel Cell with a Russian Analogue of the Aquivion Solid Polymer Electrolyte, Physical Chemestry. 464 (2015) 227-230.

[11] J.C. Dyre, Universality of ac conduction in disordered solids, Review of Modern Physics. 72 (2000) 873-919.

[12] V.V. Sinitsyn, A.I. Baranov, Compencation low and thermodynamics parameters of protonic conductivity in $\mathrm{Me}_{\mathrm{n}} \mathrm{H}_{\mathrm{m}}\left(\mathrm{AO}_{4}\right)_{\mathrm{p}}$ crystals, Ionics. 2 (1996) 478-484.

[13] C. Colosi, M. Costantini, A. Barbetta, C. Cametti, M. Dentini M., Anomalous Debye-like dielectric relaxation of water in micro-sized confined polymeric systems, Phys. Chem. Chem. Phys. 15 (2013) 20153-20160.

[14] M. Kinka, J. Banys, J. Macutkevic, A. Meskauskas, Conductivity of nanostructured mesoporous MCM-41 molecular sieve materials, Electrochimica Acta. 51 (2006) 6203-6206.

[15] X. Ling, M. Bonn, K.F. Domke, S.H. Parekh, Correlated interfacial water transportand proton conductivity in perfluorosulfonic acid membranes, Proc. Natl. Acad. Sci. USA. 116 (2019) 87158720.

[16] J.E. Thomaz, C.M. Lawler, M.D. Fayer, Proton Transfer in Perfluorosulfonic Acid Fuel Cell Membranes with Differing Pendant Chains and Equivalent Weights, J. Phys. Chem. B. 121 (2017) 4544-4553.

[17] Fr. de los Santos, F. Giancarlo, Relations between the diffusion anomaly and cooperative rearranging regions in a hydrophobically nanoconfined water monolayer, Phys. Rev. 85 (2012) 010602-010604.

[18] M.I. Ryzhkin, I.A. Ryzhkin, V.V. Sinitsyn, A.V. Klyuev, Theory of quasi-liquid surface layer, JETPh Lett. 106 (2017) 760-764.

[19] M.I. Ryzhkin, I.A. Ryzhkin, A.M. Kashin, E.A. Galitskaya, V.V. Sinitsyn, Proton conductivity in mesiporous materials, JETP Lett. 108 (2018) 596-600.

[20] M.I. Ryzhkin, A.V. Klyuev, V.V. Sinitsyn, I.A. Ryzhkin, Liquid state of hydrogen bond, JETP Lett. 104 (2016) 248-252.

[21] I.A. Ryzhkin, M.I. Ryzhkin, A.M. Kashin, E.A. Galitskaya, V.V. Sinitsyn, High proton conductivity state of water in nanoporous materials, Europhysics Letters. 126 (2019) 36003-36010. 